\title{
ACADEMIC TRANSITION: KICKING A-LEVELS INTO TOUCH
}

\author{
Joseph STEWART and Leslie ARTHUR
}

Nottingham Trent University

\begin{abstract}
From the age of 5-18, UK children are taught in a specific, grade-driven manner, imposed upon them by a rigid, competence-driven National Curriculum, which actively suppresses both creativity and innovation. With 14 years of education behind them, students often find the academic transition from A-level education (Key Stage 5) to Higher Education (HE) (National Qualifications Framework Level 4 (NQF4)) problematic. This is a particularly prominent issue with students of design and other such creative pursuits, due to the non-prescriptive nature of their chosen field(s), coupled with the fact that the number of students undertaking exciting and experimental Art and Design Foundation Diploma studies has reduced significantly in recent years.

Considering the cognitive bias of students when they embark upon HE at NQF4 and how their experiences have shaped their mind-set, it is no surprise that they arrive at university with inflexible thought processes and a somewhat superficial view of design. In other words, students are descriptively strong, but critically and analytically weak, which is the antithesis of what is required; namely an open mind, a spirit of inquiry, a self-starter approach, and, if possible, a significant work ethic. These standard variables are a prerequisite for academia and industry. They also promote innovation and independence, which are pivotal in the journey to becoming a designer.

The purpose of this paper is to assess the efficiency of an Academic Transition Framework (ATF), which has been created to facilitate a smoother progression from school to university study for product design students. The ATF was created specifically to positively change design thinking and methodologies.
\end{abstract}

\section{Keywords: Design pedagogy, Academic Transition Framework (ATF), student experience, creativity}

\section{CONTEXT}

The best teachers and education systems use creativity, innovation and inspiration to trigger a child's visceral instinct to learn. So why are creativity, innovation and inspiration knowingly suppressed by a culture of standardisation and micromanagement?

In his book, Learning (Re)imagined, Graham Brown-Martin explains why these perversities are so. Mass education was originally designed to produce the workforce required by $19^{\text {th }}$ Century factories. The desired product was workers who would sit silently at their workstations all day, behaving identically, to produce identical products, submitting to punishment if they failed to achieve the requisite standards. [1] Collaboration, creativity and critical thinking were actively discouraged by factory owners. Unfortunately, mass education in the UK has changed little since the $19^{\text {th }}$ Century, with children still dragooned into rows and made to sit still while they are coerced into learning an endless list of facts.

One must question the relevance of such as system within today's society, especially considering the myriad of data that clearly illustrates the true economic value of creative pursuits, such as design. A recent 2018 report by the Design Council, for example, states that 'the design economy generated 85.2bn in gross value added (GVA) to the UK in 2016. This is equivalent to 7\% of UK GVA and equivalent to the size of the distribution, transport, accommodation and food sectors.' [2] In spite of this evidence, our schools continue to teach skills that are not only redundant but counter-productive. The less relevant the system becomes, the harder the rules must be enforced and the greater the stress they inflict. But what are the driving forces behind such restrictive, standards-driven practices?

Pasi Sahlberg, a leading commentator on international trends in education, deftly describes the modern standards movement as the Global Education Reform Movement (GERM). [3] Having emerged in the 1980's, GERM was substantially boosted in 2000 by the league tables of the Programme for 
International Student Assessment (PISA). The aim of the PISA league tables is to provide a framework to explain, foster and assess adolescents' global competence. However, it is important to note the PISA framework is focussed on rote learning and standardised tests which only test one form of intelligence in just three areas: science, reading and mathematics. Modern education reform often has five globally common features: (i) the standardisation of education, (ii) focus on core subjects (literacy, numeracy and science), (iii) the search for low-risk ways to reach learning goals, (iv) use of corporate management tools, and (v) test-based accountability policies. [3] These features all supress creativity and innovation. GERM in the UK has led to the implementation of a 'knowledge-based curriculum', which was first introduced in its current format in 2013 by the then UK Secretary of State for Education, Michael Gove MP, who motioned that it would ensure students have a "structured stock of knowledge." [4] However, said curriculum together with an overwhelming emphasis on STEM (Science, Technology, Engineering and Mathematics) in UK schools has led to widespread standardisation and British children being amongst the most tested in the world. It must be noted at this point that this paper is not opposing the educational value of a 'stock of knowledge'. However, when students are taught to memorise a list of disconnected facts or solve sets of disconnected problems, they end up with disconnected knowledge, without any understanding of why they were learning it or how to apply it in new scenarios. [5]

There are other influential advocates of a 'knowledge-based curriculum'; namely Justine Greening MP and Nicky Morgan MP, both members of the Conservative Party who held the position of Secretary of State for Education in the UK Government between 2014 and 2018. Nicky Morgan stated that a knowledge-based curriculum will "ensure that every young person who studies it gets the same core grounding they need to succeed in further study." [6] Morgan's comments seem well intentioned; however, evidence from a major 2015 report shows us that "the growing standards movement has led to arts and creativity being squeezed out of schools". [7] The report by the Warwick Commission, entitled 'The Future Of Cultural Value', found that between 2003 and 2013 there was a 50\% drop in GCSE entries for design and technology, 23\% for drama and 25\% for other craft-related subjects. The commission also stated, "there are major concerns that the educational system is not focusing on the future needs of the cultural and creative industries and the broader needs for innovation and growth in the UK." [7]

Despite a general lack of creative education in the UK, there are many success stories that can be used as case studies for such education, most notably Finland. When the Finnish education system was in crisis forty years ago, Finland opted against standardisation and testing; instead selecting a broad and balanced curriculum, giving high priority to practical and vocational programmes and the development of creativity. Finland has consistently high standards of achievement, regularly appearing at the top or close to the top of the PISA league tables, despite the fact that there is no standardised testing apart from one examination at the end of high school. Finnish schools do not do these things in addition to achieving high standards - they achieve high standards precisely because they do these things. [8]

In his popular TED talks on creativity, Sir Ken Robinson emphasises the importance of taking risks, making mistakes and being creative. "If you're not prepared to be wrong, you'll never come up with anything original," he explains. "We're running education systems where mistakes are the worst thing you can make. We're educating people out of their creative capacities." [9] This paper provides a framework that encourages a contrasting approach.

\section{ACADEMIC TRANSITION FRAMEWORK (ATF)}

Although there is undoubtedly a need to revolutionise education from the ground up in the UK, the purpose of this study is to improve exploratory and iterative practice among HE product design students. Thus, the ATF is defined as 'a system of project-based matriculation and personalisation for HE Product Design students, specifically created to positively change design thinking and promote a culture of experimentation and reflection.'

To produce an effective ATF, three forms of understanding are required: a critique of the way things are, a vision of how they should be, and a theory of change for how to move from one to the other.

The current picture for any student of a creative discipline in the UK looks bleak. With 14 years of standardised education behind them, students often find the academic transition from A-level education (Key Stage 5) to Higher Education (HE) (National Qualifications Framework Level 4 (NQF4)) problematic. This is a particularly prominent issue with students of design and other such creative pursuits, due to the non-prescriptive nature of their chosen field(s). In years gone by, Art and Design Foundation Diploma studies helped to bridge the transition from FE to HE for creatively-orientated 
students by offering exploration, variety and excitement. However, cuts in government funding and universities dismissing the completion of this Diploma as a prerequisite for entry on to their undergraduate programmes, has led said Diploma to become somewhat of an endangered species. This in turn has resulted in students entering HE being descriptively strong, but critically and analytically weak, which is the antithesis of what is required; namely an open mind and a spirit of inquiry.

To formulate a tangible and sustainable future for product design in HE it is essential to face the reality of having to work within the current demands of the sector, which are, as time goes on, evermore strongly resembling the standards movement present throughout UK schools (and US, French and Chinese schools too). Said demands include increasing pressure on HE academics to increase the amount of 'good degrees' (2:1 or $1^{\text {st }}$ Class), increase National Student Survey (NSS) scores, increase student recruitment and decrease departmental spending. However, if the focus of education is shifted from the current pressure-cooker of results driven practise to a culture of iterative experimentation - where students understand that failure is normal, evidence shows us metrics like 'good degrees' and NSS scores will increase and graduates will be more advanced in their creative abilities.

So how do we bring about this shift? The ATF features two distinct phases, both of which encourage an exploratory and iterative approach; Stage 1 -Matriculation, and Stage 2 - Personalisation.

Stage 1 of the ATF focusses upon the first year (NQF4) and aims to facilitate the smoothest possible transition from FE to HE in a semi-structured, holistic and progressive manner. The progressive nature of matriculation is typified by three distinct modules, which serve three key developmental functions; Design Fundamentals (introduction), The Developing Product Designer (diagnostic) and Applied Product Design Practise (confirmatory).

Design Fundamentals was created with the sole purpose of giving each student a basic design 'toolkit'. Key to this module are embedding a core philosophy, skills, knowledge, language and working practise. By framing this within the confines of one holistic project, students not only develop a toolkit, but they begin to comprehend how different elements of the design process are interlinked.

The Developing Product Designer enables students to develop a deeper awareness of design; understanding its contextual and practical nature, as well as furthering core skills and expanding on design communication as a tool to develop a personalised design process.

Applied Product Design Practise develops students' understanding of design identity and context, whilst introducing how design functions as a profession. This is the beginning of the application of skills to the design world and as such will involve 'live' briefs with external companies.

Figure 1 shows the breakdown of the Matriculation stage over the course of a 30-week academic year.

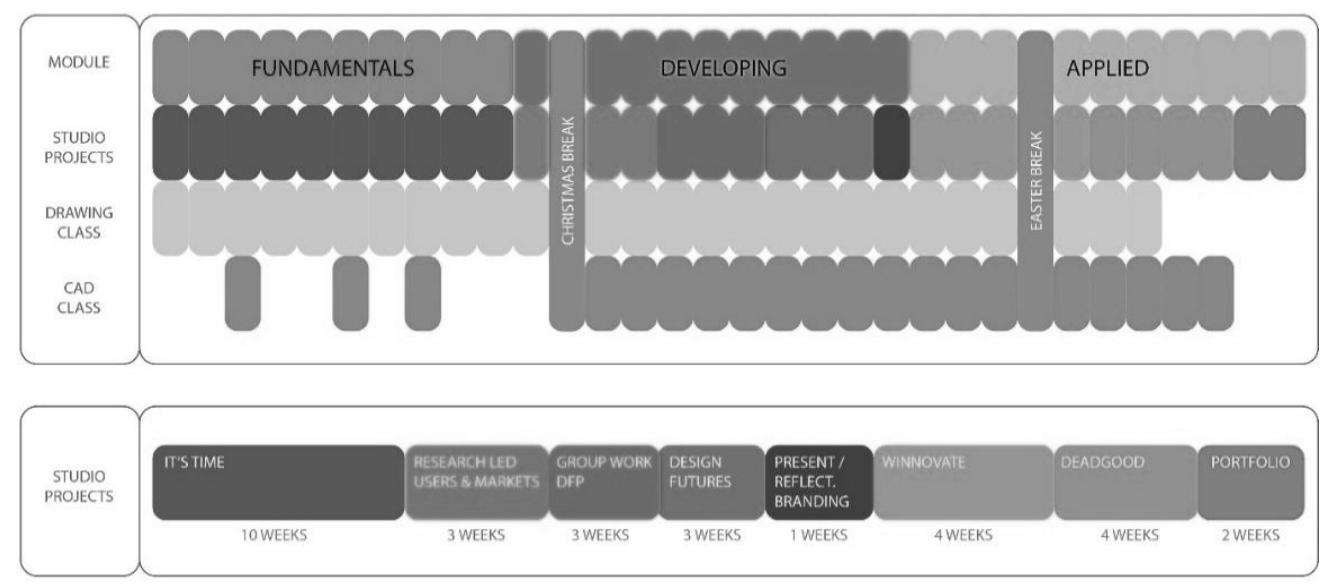

Figure 1. Matriculation Overview

Stage 2 of the ATF focusses on the second year (NQF5) and aims to provide a personalised curriculum to each student, catering to a wide range of skills and interests, whilst also placing high importance upon industrial practise and 'live' projects. To again quote Sir Ken Robinson, "Human communities depend upon a diversity of talent, not a singular conception of ability" [4]

A personalised curriculum is created not through elective modules but elective projects within set modules; the latter requiring less resources than the former. Academics collectively perform a diagnostic assessment of each student's skills, using their portfolio from NQF4, before the start of NQF5 and 
recommendations are made as to which of the elective projects would be most suitable and why. This information is then relayed to the student via email, together with a list of alternatives. It is then left to the student to create their own unique blend of projects. It is crucial that this flexible method of learning does not present a chance for students to neglect any specific skills or expertise.

Industrial practise and live projects play a pivotal role in ATF Stage 2. All projects during this stage operate in conjunction with a commercial partner. A guest lecture series, presented by a diverse range of professionals, runs alongside project work, helping to enhance students' knowledge of the industry and allowing them to identify their potential career path(s). By using a holistic, project-based context, students gain knowledge and the ability to apply it in a range of scenarios - something that cannot be achieved by any form of rote learning. Recent partners for live projects and guest lectures include the RSA, Pearson Lloyd, Herman Miller, Aston Martin, John Lewis, Nestle, Isokon, Heals and Speedo.

\section{RESULTS}

The effectiveness of the ATF has been analysed in a both a quantitative and qualitative fashion. A series of semi-structured interviews were conducted across four specific groups; namely A-level product design students (Key Stage 5), FE product design academics, $1^{\text {st }}$ year product design students (NQF4) and HE product design academics.

Quantitative data collection involved a comparison between average attainment and attendance from two different cohorts of NQF4 product design students, over the course of the ATF Matriculation stage; Cohort A having followed the ATF model and Cohort B having followed a more traditional structure (see Figure 2). Unfortunately, the effect of the ATF Personalisation stage could not be assessed quantitatively as this framework has not been in operation for a long enough period.
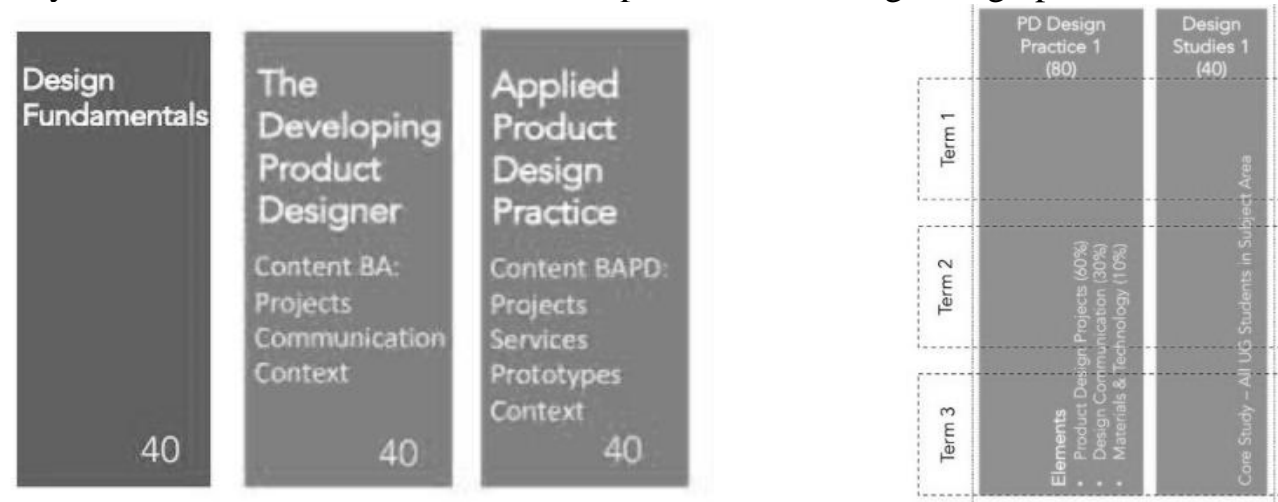

Figure 2: Comparison of ATF Model (left) and traditional structure (right)

Data shows that whilst Cohort B had an average attainment of $56 \%$ and average attendance of $73 \%$, Cohort A, who followed the ATF model had an average attainment of $63 \%$ and average attendance of $89 \%$. Whilst there has been an improvement in both metrics using the ATF, the most notable effect has been the unquantifiable increase in student engagement and morale.

Qualitative data presented many interesting considerations. A group of 28 A-level students stated "learning how to design" as the only real important part of their education to date. The phrasing of this answer implies that there is a singular, linear approach to every design process. This mindset suppresses experimentation and dismisses other crucial factors in the development of designers, such as ideation, problem solving and innovation.

Feedback from two FE academics, with a combined experience of 33 years also raised several important issues. When asked if they considered A-levels liberating or restrictive, both commented on the restrictive nature of A-level studies, although both also stated that it is the role of the teacher to "liberate and broaden the students' views beyond the textbook". When asked about the extent to which exploration encouraged in school, both academics said that it is "very dependent on the school". Unfortunately, increasing demands to raise standards of attainment continue to impact upon many teachers' ability to liberate students by encouraging exploration and inquiry, thereby reducing morale. A group of 20 NQF4 product design students, who are currently studying under the ATF model added a students' perspective of design education. In contrast to the A-level students, this group believed the 'ability to create ideas' as the most important part of their HE education. Moreover, the importance of a 
"diverse skill set" including "research, experimentation, reflection and visual communications" was highly valued by most of the group.

The NQF4 students spoke with great excitement and anticipation when asked about the Personalisation Stage of the ATF, which they should progress to in the 2019-20 academic year. Comments included "it's great that we get to create our own selection of projects - it makes our experience personal" and "the ability to choose projects will allow me to focus on my interests".

A group of eight HE Product Design academics, all of whom have taught under the ATF model and a more traditional structure, shown in Figure 2, were asked to give their thoughts on both. Every member of the group favours the ATF model; comments included "the ATF brings a personalised curriculum within the confines of an institutionally enforced standards culture". However, many of the group did express worry over the growing standards movement in HE with one academic commented "aren't universities just as guilty about getting the right results," when asked to define the key differences between FE and HE.

\section{CONCLUSIONS}

In HE, students are uncensored in their criticism of a curriculum if it is not engaging or does not produce their desired level of attainment. This often leads HE institutions to orientate their entire academic strategies around raising attainment across the board. This seems well judged; however, evidence shows that a culture of academicism totally neglects the very skills that employers say they need in the modern world; namely creativity, adaptability and teamwork. In contrast, the ATF uses the students' interests to guide academic practise, acting as a safety net when developing ideas. This acts as a launchpad for students to make the connections between the brief and their response, promoting constant engagement. It has been shown that the ATF is successful in several respects; student attainment, engagement and morale, and staff morale. Although only proven effective within a Product Design-specific context, the ATF model could be adapted to suit other fields. All NQF4 structures require introductory, diagnostic and confirmatory components, and personalised learning is unquestionably successful at any level.

The ATF highlights a pressing need to help young people develop as creative thinkers so that they're prepared for life in a fast-changing world. As Mitchel Resnick puts it, "one of the best ways to help young people prepare for life in a creative society is to make sure that they have the chance to follow their interests, to explore their ideas, to develop their voices." [5]

\section{REFERENCES}

[1] Brown-Martin G. (2014). Learning (Re)imagined. London: Bloomsbury Academic.

[2] Design Council. (2018) The Design Economy 2018. Available: https://www.designcouncil.org.uk/resources/report/design-economy-2018 (Accessed: 24 Feb 2019).

[3] Sahlberg P. (2014). Finnish Lessons 2.0: What Can the World Learn from Educational Change in Finland? (Series on School Reform). New York: Teachers College Press.

[4] Coughlan S. (2013). Gove sets out 'core knowledge' curriculum plans. Available: https://www.bbc.co.uk/news/education-21346812. (Accessed 30th Jan 2019).

[5] Resnick M (2017). Lifelong Kindergarten. Cambridge: MIT Press.

[6] Morgan N. (2015). Nicky Morgan: why knowledge matters. Available: https://www.gov.uk/government/speeches/nicky-morgan-why-knowledge-matters. (Accessed: 30th Jan 2019).

[7] The Warwick Commission. (2015) Enriching Britain: Culture, Creativity and Growth. Available: https://warwick.ac.uk/research/warwickcommission/futureculture/finalreport (Accessed: 19th Jan 2019).

[8] Robinson K. (2016). Creative Schools: Revolutionising Education from the Ground Up. London: Penguin.

[9] Robinson K. (2006). Do schools kill creativity? Available: https://www.ted.com/talks/ken_robinson_says_schools_kill_creativity/transcript?language=en\#t318689. (Accessed: 28th Jan 2019).

[10] Robinson K (2017). Out of Our Minds. 3rd ed. Minnesota: Capstone. 